\title{
A Comparative Study on Primary Bearing Rating Life of a 5-MW Two-Blade Wind Turbine System Based on Two Different Control Domains
}

\author{
Bon-Yong Koo (D) and Dae-Yi Jung * \\ School of Mechanical Convergence System Engineering, Kunsan National University, Gunsan 54150, Korea \\ * Correspondence: dyjung@kunsan.ac.kr; Tel.: +82-63-469-4874
}

Received: 8 May 2019; Accepted: 4 July 2019; Published: 6 July 2019

check for updates

\begin{abstract}
Recently, the importance of individual pitch control (IPC) capability in wind turbine systems has been emphasized to achieve the desired power performance and mitigate the aerodynamic imbalance load for the mechanical integrity. Compared to collective pitch control (CPC), which assigns identical pitch angles for all employed blades, IPC is capable of generating other various sets of pitch angles to manipulate the aerodynamic load. Thus, the mechanical elements of wind turbine systems may take advantages from this variation, which allows wind turbines to have lighter designs and longer lifetimes. One of the essential mechanical components in the wind turbine is a primary bearing supporting the blades-rotor-shaft unit, which has not been fully investigated yet among the structural elements in the wind turbine system. In this regard, this research focuses on predicting the bearing life span of a NACA64-A17 two-blade 5-MW wind turbine system for the domains of allowable individual pitch angles by IPC. In particular, under the effect of various wind speeds, a bearing life span was determined based on the average value of load cases-satisfying both appropriate power level and the allowable domain of pitch control angles, which were possibly conveyed by IPC - and the result was compared with the bearing life predicted based on the domain of pitch angles, as generated by the CPC strategy. Consequently, in the ranges of high wind speeds, it was found that the average applied load to the bearing is reduced under the domain of the IPC-based pitch angle, resulting in possibly increasing the life span of the bearing. With the presented results, it is hoped that this work will provide important insights for those that majorly concern designing the primary bearing of the IPC-based wind turbine system.
\end{abstract}

Keywords: wind turbine system; bearing rating life; collective pitch control (CPC); individual pitch control (IPC)

\section{Introduction}

With the growing importance of wind energy as an electrical power generation source, lifetime extension and the maintenance cost reduction of large-scale wind turbines are the key challenging parameters to wind industries with an emphasis on robustness and reliability enhancement. From the field failure data [1] and Failure Modes and Effects Analysis (FMEA) [2] for wind turbines, the failure modes of wind turbines can be listed as material failure, fracture, electrical failure, structural and mechanical failures, etc. Among the mechanical components, the rotor system, including the pitch control system and blades is more vulnerable than others in terms of failure rate.However, one of the critical mechanical components in wind turbines is a main shaft spherical roller bearing (SPB) $[3,4]$ to support the turbine thrust and acting forces, of which failures usually require the complete removal of the drivetrain system and a land shop-based repair.

To improve the structural reliability [5] and integrity of wind turbine components, two groups of fault estimation or life prediction methods are categorized: the model-based method, which utilizes the 
physical model or state model approximation, and the data-driven method, which solely relies on the measured sensor data [6]. In the first group, Vidal et al. [7] used a physical model of the turbine pitch actuator for fault diagnosis and fault-tolerant control. Niebsch and Ramlau [8,9] used a finite element model of the wind turbine to reconstruct the mass imbalance and aerodynamic imbalance. In [10], a fuzzy augmented system model was adopted to estimate system faults and develop tolerant control techniques. In the second group, Kusiak et al. [11] used a datamining-based prediction approach to monitor blade pitch faults, and [6] developed a statistical approach to abstract and predict wind turbine bearing states in an online manner based on temperature measurement. Yang et al. [12,13] highlighted conditional monitoring methods and technologies to achieve high reliability and a low generation cost of wind energy. A recent review paper [14] for the special issue, "Real-time monitoring, prognosis, and resilient control for wind turbine systems" provided a state-of-the-art overview of monitoring, fault diagnosis, and life prediction for wind turbine systems as well as resilient control and optimization.

Individual pitch control (IPC) [15] to control the power output of each blade independently plays a key role in extending the fatigue life of wind turbines. According to the article [16], "the main benefit of IPC is the reduction of fatigue loads on the rotor blades, the hub, and mainframe and tower structures. In order to compensate these loads, especially by inhomogeneous wind fields, the pitch of each rotor blade has to be adjusted independently from the other blades. A reduction of fatigue loads has two considerable advantages: it allows lighter designs and translates into longer lifetimes of wind turbines." Numerical simulations of the wind turbine by Gong and Qiao [17] show that mass and aerodynamic imbalances perturb an electric output power and structural loads. In particular, IPC is an imbalance compensation solution of wind turbines if the asymmetric wind shear effect is present. To realize the IPC of wind turbine blades, a range of multivariable control algorithms has been developed $[18,19]$.

To implement the IPC control strategy in large wind turbines, a physical understanding of the blade rotor system and bearing reaction under inhomogeneous wind shear is important. This paper originally predicts the bearing life cycle of a two 5-MW NACA64-A17 blade wind turbine system under the aerodynamic imbalance induced by the combinations of allowable individual pitch angles. Although many scientific investigations have discussed the load mitigation alongside a blades pitch angle regulated control system for main structural components such as the blades, hub, and tower, the influence of such control strategies for the lifetime of a primary bearing has not been fully explored yet. Therefore, right here in, we conduct a comparative study of the bearing life for the domains of both IPC and CPC to provide important insights that enable other researchers to design and select the primary bearing of the IPC-based wind turbine system. This paper is organized as follows. In Section 2, the physical wind turbine system is modeled to evaluate the bearing load component by the wind turbine rotor. In Section 3, the life prediction method of a main shaft spherical roller bearing is proposed from the reaction force. In Section 4, the actual life of the bearing is numerically calculated. Finally, conclusions are drawn in Section 5.

\section{Wind Turbine System Model}

In this section, to facilitate the bearing load evaluation and the life prediction, the mathematical model of the wind turbine system under the influence of an inhomogeneous wind shear effect has been developed. As depicted in Figure 1, the proposed system is equipped with two blades opposed to each other in 180-degree phases and arranged with IPC capability.

Considering the arbitrary rotational angle $(\varphi)$ of a rotor and the radial location $(r)$ of a blade, the particular height $h(r, \varphi)$ of the blade element with respect to the ground is given by:

$$
h(r, \varphi)=Z_{0}+r \sin (\varphi)
$$


The profile of wind velocity $V(r, \varphi)$ is expressed in terms of the particular height:

$$
V(r, \varphi)=V_{m}\left(\frac{h(r, \varphi)}{Z_{0}}\right)^{K}=V_{m}\left(\frac{Z_{0}+r \sin (\varphi)}{Z_{0}}\right)^{K}
$$

where $Z_{0}$ and $V_{m}$ are the height of the hub and the wind speed at the hub, respectively. The wind shear exponent $K$ is set to 0.3 , assuming complex terrain.

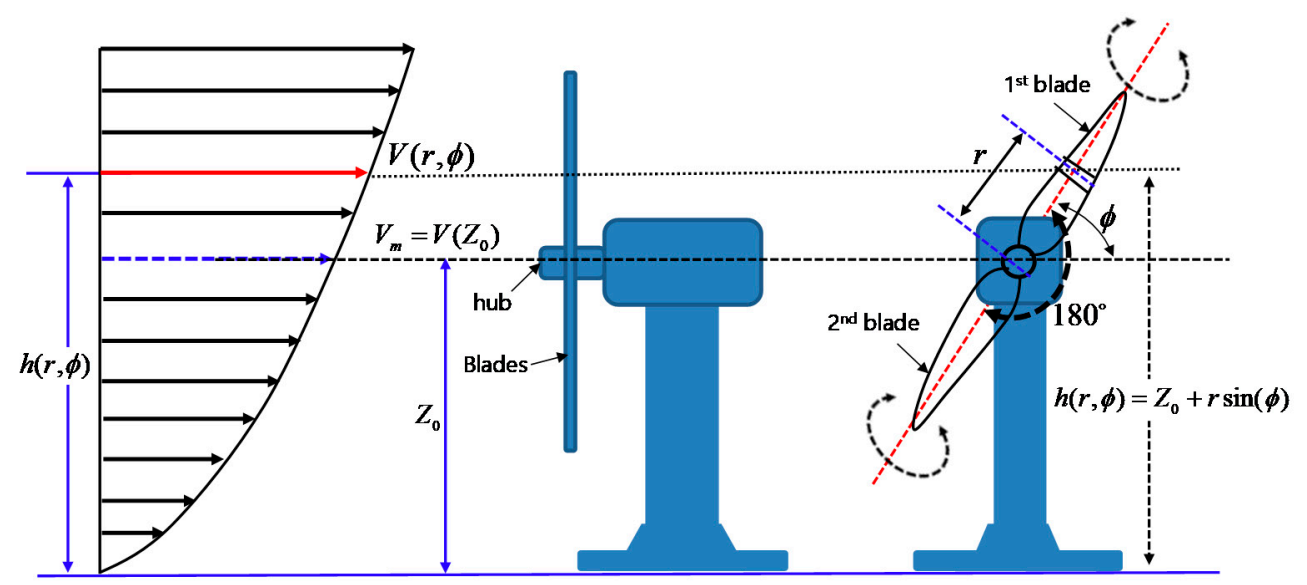

Figure 1. Individual pitch control (IPC)-based two-blade wind turbine system under the wind shear effect.

Directional aerodynamic forces acting upon a blade element are shown in Figure 2. Here, the bladesrotor is assumed to be driven at an angular speed $\Omega$; thus, a tangential velocity $r \Omega$ with respect to the tangential line shown in Figure 2 is induced at an arbitrary local radial location $r$ from the center of the hub.

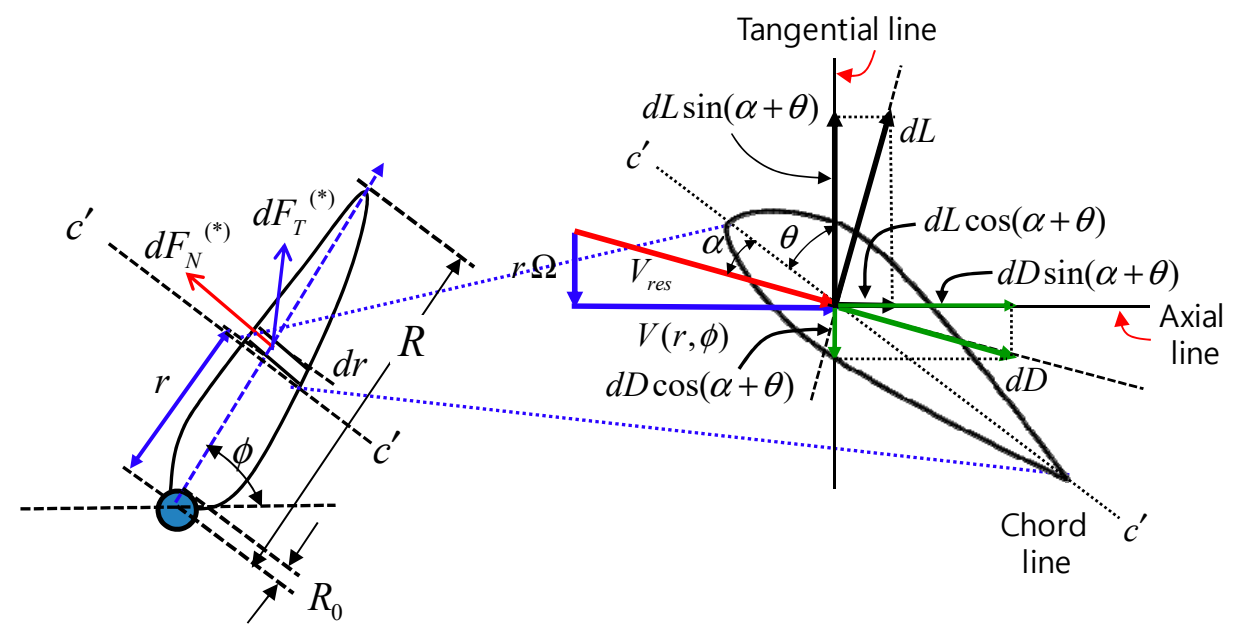

Figure 2. Blade element velocities and aerodynamic forces with respect to the blade local coordinate frame with the chord line $\left(c^{\prime}-c^{\prime}\right)$ as a reference.

Consequently, the angle of attack $\alpha(r, \varphi)$ for the local blade element is provided by:

$$
\alpha(r, \varphi)=\tan ^{-1}\left[\frac{V(r, \varphi)}{r \Omega}\right]-\theta=\tan ^{-1}\left[\frac{V(r, \varphi)}{r \Omega}\right]-\left(\theta_{0}+\theta_{c}\right)
$$

where $\theta$ is the local blade pitch angle measured from the tangential line (in Figure 2) to the chord line $\left(c^{\prime}-c^{\prime}\right)$. Here, the blade pitch angle is divided into two parts, $\theta_{0}$ and $\theta_{\mathcal{c}}$, which are a designed local 
blade pitch angle at $r$ and the varying pitch angle contributed by a control system such as IPC or the traditional collective pitch control (CPC).

The resultant relative wind velocity created on each blade element is followed by:

$$
V_{\text {res }}(r, \varphi)=\sqrt{V(r, \varphi)^{2}+(r \Omega)^{2}}
$$

Thus, the local lift force $(d L(r, \varphi))$ and drag one $(d D(r, \varphi))$ for a blade element can be obtained by:

$$
\begin{gathered}
d L(r, \varphi)=\frac{1}{2} \cdot \rho_{\text {air }} \cdot C_{L}(\alpha) \cdot V_{\text {res }}(r, \varphi)^{2} \cdot c(r) \cdot d r \\
=\frac{1}{2} \cdot \rho_{\text {air }} \cdot C_{L}(\alpha) \cdot\left[V(r, \varphi)^{2}+(r \Omega)^{2}\right] \cdot c(r) \cdot d r \\
\begin{aligned}
d D(r, \varphi)= & \frac{1}{2} \cdot \rho_{\text {air }} \cdot C_{D}(\alpha) \cdot V_{r e s}(r, \varphi)^{2} \cdot c(r) \cdot d r \\
= & \frac{1}{2} \cdot \rho_{\text {air }} \cdot C_{D}(\alpha) \cdot\left[V(r, \varphi)^{2}+(r \Omega)^{2}\right] \cdot c(r) \cdot d r
\end{aligned}
\end{gathered}
$$

where $\rho_{\text {air }}, c(r)$ and $d r$ are an air density, a local chord length, and a finite radial length, respectively. $C_{L}(\alpha)$ and $C_{D}(\alpha)$ are the lift and drag coefficients, which are a function of the angle of attack $(\alpha)$.

The local axial force $\left(d F_{T}(r, \varphi)\right)$ and tangential one $\left(d F_{N}(r, \varphi)\right)$ are identified by resolving the components of lift and drag forces in Equations (5) and (6):

$$
\begin{aligned}
& d F_{T}(r, \varphi)=d L(r, \varphi) \cdot \cos \left(\alpha+\theta_{0}+\theta_{c}\right)+d D(r, \varphi) \cdot \sin \left(\alpha+\theta_{0}+\theta_{c}\right) \\
& d F_{N}(r, \varphi)=d L(r, \varphi) \cdot \sin \left(\alpha+\theta_{0}+\theta_{c}\right)-d D(r, \varphi) \cdot \cos \left(\alpha+\theta_{0}+\theta_{c}\right)
\end{aligned}
$$

The total axial forces $\left(F_{\text {T.Total }}(\varphi)\right)$ generated by the first blade can be calculated by integrating Equation (7) from the initial radial location $\left(R_{0}\right)$ to the tip of the blade, $(R)$ :

$$
F_{T . T o t a l}(\varphi)=\int_{R_{0}}^{R} d F_{T .}(r, \varphi)
$$

Also, as shown in Figure 3, the moment induced by $F_{T . T o t a l}(\varphi)$ on a blade with respect to the fixed frame $\left\{n_{1} n_{2} n_{3}\right\}$ can be obtained by:

$$
\begin{gathered}
\mathbf{M}_{\text {T.Total }}(\varphi)=M_{\text {T.Total.X }}(\varphi) \cdot n_{1}+M_{\text {T.Total. } Y}(\varphi) \cdot n_{2} \\
M_{\text {T.Total.X }}(\varphi)=\sin [\varphi] \int_{R_{0}}^{R} r \cdot d F_{T .}(r, \varphi) \\
M_{\text {T.Total. } Y}(\varphi)=\cos [\varphi] \int_{R_{0}}^{R} r \cdot d F_{T}(r, \varphi)
\end{gathered}
$$




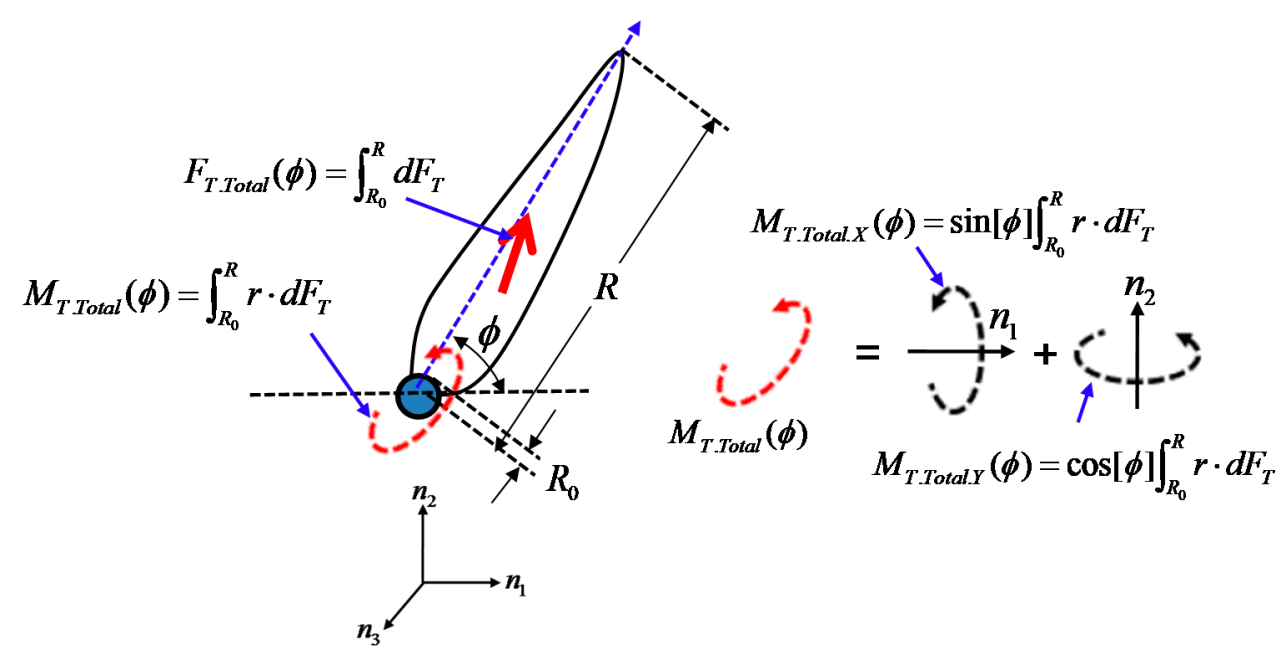

Figure 3. Total axial force $F_{\text {T.Total }}(\varphi)$ and moment $M_{\text {T.Total }}(\varphi)$ induced by $F_{\text {T.Total }}(\varphi)$.

From now on, the subscript $i$ has been added to the variables $d F_{T}(r, \varphi)$ and $d F_{r}(r, \varphi)$ (i.e., $d F_{T . i}(r, \varphi)$ and $d F_{r . i}(r, \varphi)$ for $\left.i=1,2\right)$ to denote the forces acting on the $i$-th. Therefore, the total axial force and moments due to both blades are given by:

$$
\begin{gathered}
F_{\text {T.Total.d }}(\varphi)=\sum_{i=1}^{2} \int_{R_{0}}^{R} d F_{T . i}(r, \varphi+\pi(i-1)) \\
M_{\text {T.Total.X.d }}(\varphi)=\sum_{i=1}^{2}\left\{\sin [\varphi+\pi(i-1)] \int_{R_{0}}^{R} r \cdot d F_{T . i}(r, \varphi+\pi(i-1))\right\} \\
M_{\text {T.Total.Y.d }}(\varphi)=\sum_{i=1}^{2}\left\{\cos [\varphi+\pi(i-1)] \int_{R_{0}}^{R} r \cdot d F_{T . i}(r, \varphi+\pi(i-1))\right\}
\end{gathered}
$$

On the other hand, based on Equation (8), the total tangential force of one blade becomes:

$$
F_{N . T o t a l}(\varphi)=\int_{R_{0}}^{R} d F_{N}(r, \varphi)
$$

As described in Figure 4, Equation (12) can be decomposed into two directional forces, $F_{N . T o t a l . X}(\varphi)$ and $F_{\text {N.Total. } Y}(\varphi)$, with respect to the fixed frame $\left\{\begin{array}{lll}n_{1} & n_{2} & n_{3}\end{array}\right\}$ :

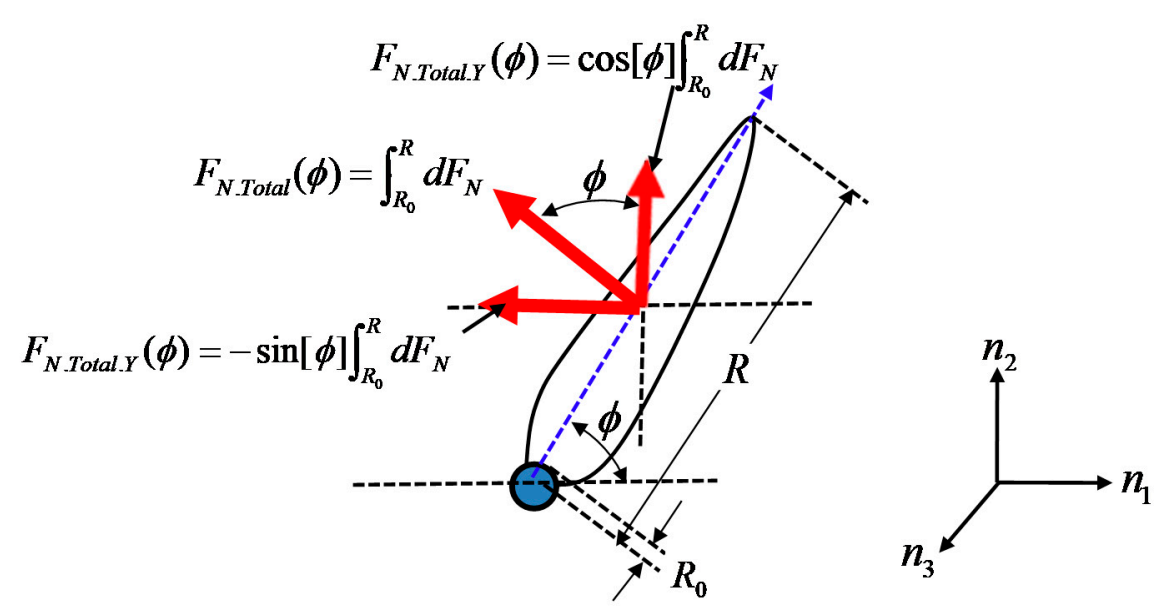

Figure 4. Total tangential forces generated by one blade. 
The horizontal and vertical components of the total tangential force via both blades are given by:

$$
\begin{gathered}
F_{N . T o t a l . X . d}(\varphi)=-\sum_{i=1}^{2}\left\{\sin [\varphi+\pi(i-1)] \int_{R_{0}}^{R} d F_{N . i}(r, \varphi+\pi(i-1))\right\} \\
F_{N . \text { Total.Y.d }}(\varphi)=\sum_{i=1}^{2}\left\{\cos [\varphi+\pi(i-1)] \int_{R_{0}}^{R} d F_{N . i}(r, \varphi+\pi(i-1))\right\}
\end{gathered}
$$

Alternatively, the continuous domain integral for Equation (11) is replaced by:

$$
\begin{gathered}
F_{\text {T.Total.d }}(\varphi) \approx \sum_{i=1}^{2} \sum_{j=0}^{n} \Delta F_{T . i}\left(r_{j}, \varphi+\pi(i-1)\right) \\
M_{\text {T.Total.X.d }}(\varphi) \approx \sum_{i=1}^{2} \sum_{j=0}^{n} \sin [\varphi+\pi(i-1)] \cdot r_{j} \cdot \Delta F_{T . i}\left(r_{j}, \varphi+\pi(i-1)\right) \\
M_{\text {T.Total.Y.d }}(\varphi) \approx \sum_{i=1}^{2} \sum_{j=0}^{n} \cos [\varphi+\pi(i-1)] \cdot r_{j} \cdot \Delta F_{T . i}\left(r_{j}, \varphi+\pi(i-1)\right)
\end{gathered}
$$

where $n$ is the segments of the blade element along the radial direction. Also, $r_{j}=R_{0}+\Delta R \cdot j$ and $\Delta R=\left(R-R_{0}\right) / n$. Since Equation (14) is discretized, its accuracy highly depends on the number of segment $n$. Therefore, the selection of $n$ has been discussed through simulations in the Section 4 . Similarly, Equation (13) is expressed by:

$$
\begin{aligned}
& F_{\text {N.Total.X.d }}(\varphi) \approx-\sum_{i=1}^{2} \sum_{j=0}^{n} \sin [\varphi+\pi(i-1)] \cdot \Delta F_{N . i}\left(r_{j}, \varphi+\pi(i-1)\right) \\
& F_{\text {N.Total.Y.d }}(\varphi) \approx \sum_{i=1}^{2} \sum_{j=0}^{n} \cos [\varphi+\pi(i-1)] \cdot \Delta F_{N . i}\left(r_{j}, \varphi+\pi(i-1)\right)
\end{aligned}
$$

The aerodynamic forces and moments generated by both blades in Equations (14) and (15) will be utilized to obtain the reaction forces acting on the primary bearing in Section 3.

Additionally, based on Equation (14a), the total power of the proposed system can be accomplished by:

$$
\begin{gathered}
P_{\text {T.Total }}(\varphi(t)) \approx \lim _{t \rightarrow \infty} T_{\text {T.Total }}(\varphi(t)) \cdot \Omega(t) \\
T_{\text {T.Total }}(\varphi(t)) \approx \sum_{i=1}^{2} \sum_{j=0}^{n} r_{j} \cdot \Delta F_{N . i}\left(r_{j}, \varphi(t)+\pi(i-1)\right)
\end{gathered}
$$

where $T_{\text {T.Total }}(\varphi(t))$ is the total rotational torque due to both blades.

The rotational speed of the rotor $\Omega(t)$ in Equation (16a) can be determined by the following dynamics for a rotor-generator:

$$
\begin{gathered}
J_{r} \dot{\Omega}(t)=T_{T . \text { Totoal }}(\varphi(t))-C_{s}\left(\Omega(t)-\dot{\varphi}_{g}(t) / N_{g}\right)-K_{s}\left(\varphi(t)-\varphi_{g}(t) / N_{g}\right) \\
J_{g} N_{g} \ddot{\varphi}_{g}(t)=-T_{g} N_{g}+C_{s}\left(\dot{\varphi}(t)-\dot{\varphi}_{g}(t) / N_{g}\right)+K_{s}\left(\varphi(t)-\varphi_{g}(t) / N_{g}\right)
\end{gathered}
$$

where, $\varphi_{g}(t), J_{r}$, and $J_{g}$ are respectively the rotational angle of the generator shaft, the rotational inertia of the rotor and generator, and $C_{S}$ and $K_{s}$ are the twisted angular damping and stiffness coefficient of the shaft. Also, $T_{g}$ is the countertorque from the generator, and $N_{g}$ is the ratio of the gearbox between the rotor and the generator. 


\section{Bearing Rating Life Prediction}

To predict the basic rating life of primary bearing for the wind turbine system, it is necessary to determine the reaction force of the bearing. For further analysis, the following blades-rotor-bearing-geared generator integrity has been depicted in Figure 5 together with the aerodynamic forces and moments in Equations (14) and (15).The reaction forces on each component

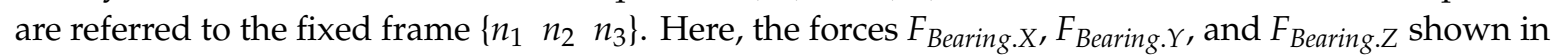
Figure 5 represent the decomposed reaction forces of the bearing with respect to $\left\{\begin{array}{lll}n_{1} & n_{2} & n_{3}\end{array}\right\}$, while $F_{\text {others.X }}, F_{\text {others. } Y}$, and $F_{\text {others. } Z}$ indicate the supporting forces due to a geared generator unit.

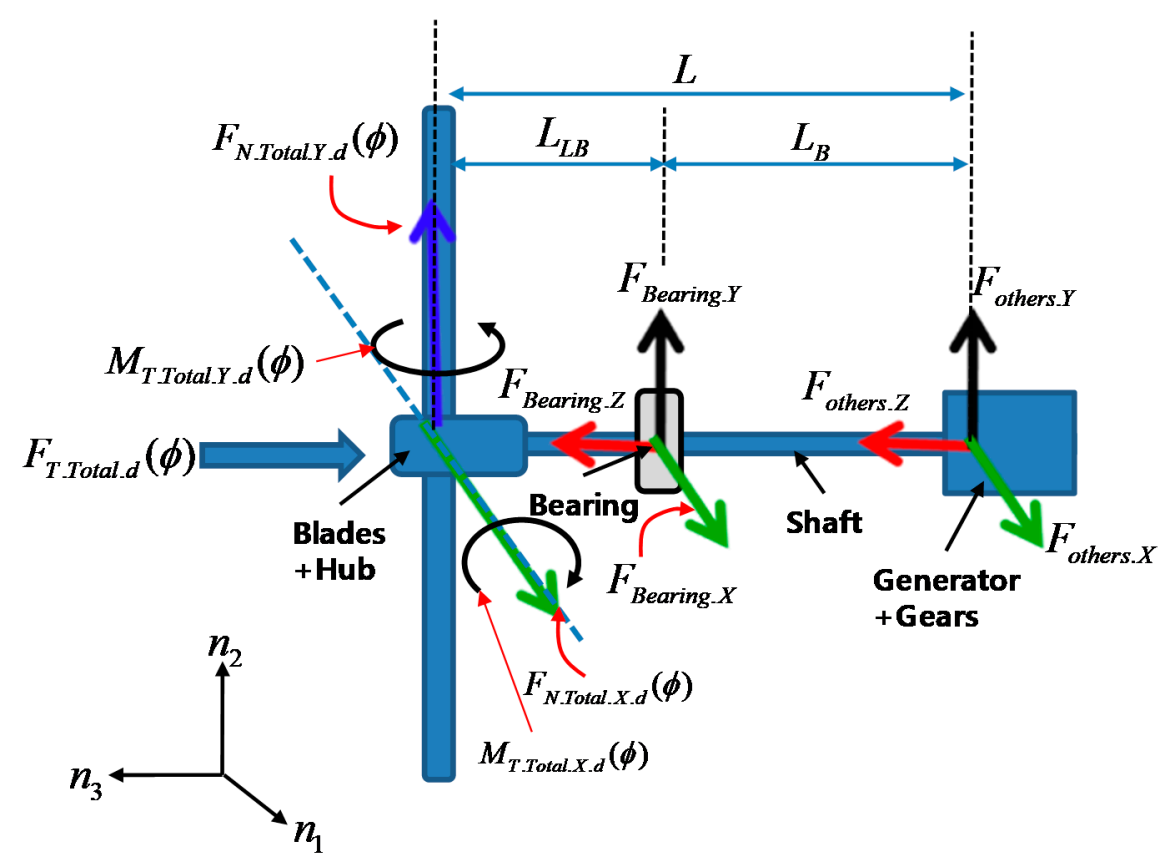

Figure 5. Free Body Diagram (FBD) of the blades-rotor-bearing-geared generator integrity.

With respect to the $n_{1}$-direction, the summation of forces and moments results in:

$$
\begin{gathered}
F_{\text {N.Total.X.d }}(\varphi)+F_{\text {Bearing.X }}+F_{\text {others.X }}=0 \\
F_{\text {N.Total.X.d }}(\varphi) \cdot L+F_{\text {Bearing.X. }} L_{B}-M_{\text {T.Total.Y.d }}(\varphi)=0
\end{gathered}
$$

where $L$ and $L_{B}$ are the full length of the shaft and the distance between the axial locations of bearing and the geared generator.

Along with the $n_{2}$ direction, the forces and moments yield:

$$
\begin{gathered}
F_{\text {N.Total.Y.d }}(\varphi)+F_{\text {Bearing.Y }}+F_{\text {others.Y }}=0 \\
F_{\text {N.Total.Y.d. }}(\varphi) \cdot L+F_{\text {Bearing.Y. }} L_{B}+M_{\text {T.Total.X.d }}(\varphi)=0
\end{gathered}
$$

For the $n_{3}$ direction, all the resultant forces produce:

$$
\begin{gathered}
F_{\text {T.Total.d }}(\varphi)=F_{\text {Bearing. } Z}+F_{\text {others. } Z} \\
F_{\text {Bearing. } Z}=f \cdot F_{\text {others. } Z}
\end{gathered}
$$

where the parameter $f$ is the ratio of the reaction forces between $F_{\text {Bearing. } Z}$ and $F_{\text {others. } Z \text {. }}$ 
Placing Equations (18) through (20) into matrix form:

$$
\left[\begin{array}{cccccc}
1 & 1 & 0 & 0 & 0 & 0 \\
1 & 0 & 0 & 0 & 0 & 0 \\
0 & 0 & 1 & 1 & 0 & 0 \\
0 & 0 & 1 & 0 & 0 & 0 \\
0 & 0 & 0 & 0 & 1 & 1 \\
0 & 0 & 0 & 0 & 1 & -f
\end{array}\right]\left[\begin{array}{c}
F_{\text {Bearing.X }} \\
F_{\text {others.X }} \\
F_{\text {Bearing.Y }} \\
F_{\text {others.Y }} \\
F_{\text {Bearing.Z }} \\
F_{\text {others. } Z}
\end{array}\right]=\left[\begin{array}{c}
-F_{N . T o t a l . X . d}(\varphi) \\
-F_{\text {N.Total.X.d }}(\varphi) \cdot L / L_{B}+M_{\text {T.Total.Y.d }}(\varphi) \\
-F_{\text {N.Total.Y.d. }}(\varphi) \\
-F_{\text {N.Total.Y.d. }}(\varphi) L-M_{\text {T.Total.X.d }}(\varphi) \\
F_{\text {T.Total.d }}(\varphi) \\
0
\end{array}\right]
$$

The unknown forces can be identified by solving Equation (21), and it is easily seen that the reaction forces of bearing $F_{\text {Bearing.X }}, F_{\text {Bearing. } Y}$, and $F_{\text {Bearing.Z }}$ are the function of the rotation angle, $\varphi$.

Under the assumption that the rotational speed of the rotor reaches a steadystate, at particular control pitch angles $\left(\theta_{c .1}, \theta_{c .2}\right)$, for a full rotation $0^{\circ} \leq \varphi(t) \leq 360^{\circ}$, the average steady-state force of the bearing in the radial direction can be provided by:

$$
F_{\text {ave.radial }}\left(\theta_{c .1}, \theta_{c .2}\right)=\underset{0 \leq \varphi(t) \leq 360^{\circ}}{\operatorname{ave}} \lim _{t \rightarrow t_{\infty}} \sqrt{F_{\text {Bearing.X }}\left(\varphi(t), \theta_{c .1}, \theta_{c .2}\right)^{2}+F_{\text {Bearing. } Y}\left(\varphi(t), \theta_{c .1}, \theta_{c .2}\right)^{2}}
$$

Similarly, the average steady-state force of the bearing along the axial direction is:

$$
F_{\text {ave.axial }}\left(\theta_{c .1}, \theta_{c .2}\right)=\underset{0 \leq \varphi(t) \leq 360^{\circ}}{\operatorname{ave}} \lim _{t \rightarrow t_{\infty}}\left|F_{\text {Bearing. } z}\left(\varphi(t), \theta_{c .1}, \theta_{c .2}\right)\right|
$$

In this study, it is assumed that the average forces in Equations (22) and (23) are treated as a fundamental basis to determine the final representative ones for predicting a bearing life span.

Next, it is crucial for us to find out the sets of blade pitch angles $\left(\theta_{c .1}, \theta_{c .2}\right)$ that possibly contributed by IPC. For that purpose, let's consider the following domain of blade pitch angles depicted in Figure 6 .

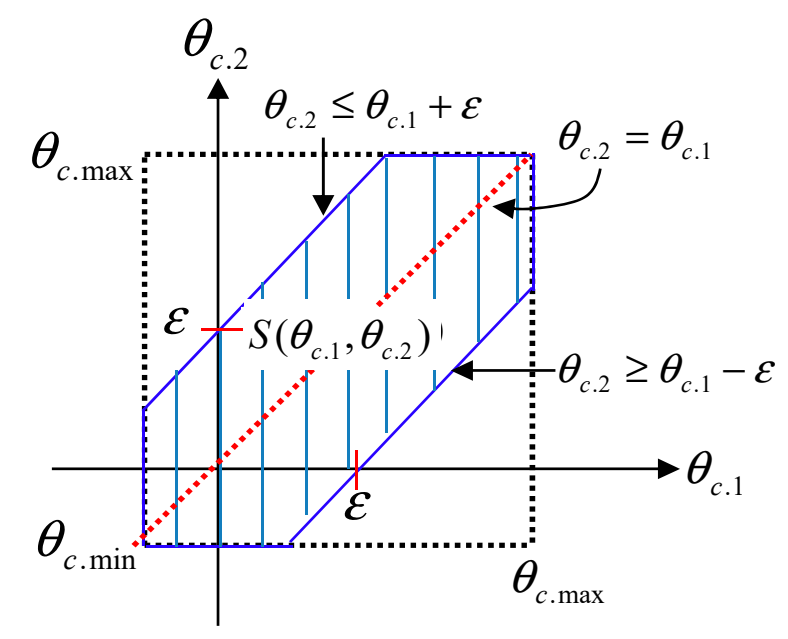

Figure 6. Proposed operational domain for blade pitch angles $S\left(\theta_{c .1}, \theta_{c .2}\right)$.

Specifically, the proposed operational domain $S\left(\theta_{c .1}, \theta_{c .2}\right)$ is given by:

$$
S\left(\theta_{c .1}, \theta_{c .2}\right)=\left\{\theta_{c .1}, \theta_{c .2} \mid \theta_{c . \min } \leq \theta_{c .1}, \theta_{c .2} \leq \theta_{c . \max }, \theta_{c .2} \geq \theta_{c .1}-\varepsilon, \theta_{c .2} \leq \theta_{c .1}+\varepsilon\right\}
$$

where $\theta_{c \text {.min }}$ and $\theta_{c \text {.max }}$ are the minimum and maximum admissible pitch angles via IPC, respectively. Also, $\varepsilon$ is the parameter to manipulate the area of $S\left(\theta_{c .1}, \theta_{c .2}\right)$.

It is well known that the control strategy of the IPC is usually developed based on the fundamental control sets of the CPC. Therefore, it is reasonable to assume that the set of blade pitch angles generated by the IPC belongs to the extended region, i.e., the shaded area in Figure 6 based on $\theta_{c .1}=\theta_{c .2}$. 
Additionally, we should confirm that the selected domain $S\left(\theta_{c .1}, \theta_{c .2}\right)$ contains the region for the desired power level of the wind turbine system.

Upon this request, the average steady-state power for a full rotation of the rotor is selected for whether the system produces a desired power level or not and is given by:

$$
P_{\text {T.Total.SS.ave }}\left(\theta_{c .1}, \theta_{c .2}\right) \approx \underset{0 \leq \varphi(t) \leq 360^{\circ}}{\operatorname{ave}} \underset{t \rightarrow t_{\infty}}{\lim } P_{\text {Total }}(\varphi(t))
$$

Defining the set of desired power as:

$$
S_{P}\left(\theta_{c .1}, \theta_{c .2}\right)=\left\{\theta_{c .1}, \theta_{c .2} \mid P_{\min } \leq P_{\text {T.Total.SS.ave }}\left(\theta_{c .1}, \theta_{c .2}\right) \leq P_{\max }\right\}
$$

where $P_{\min }$ and $P_{\max }$ are the minimum and maximum regulated power of a 5-MW wind turbine system, respectively. In this study, we choose $P_{\min }$ and $P_{\max }$ as $4.8 \mathrm{MW}$ and 5.2 MW, respectively.

By adjoining the domain in Equation (24) with the constraints in Equation (26) generate the new domain to focus on:

$$
S_{I}\left(\theta_{c .1}, \theta_{c .2}\right)=S\left(\theta_{c .1}, \theta_{c .2}\right) \cap S_{P}\left(\theta_{c .1}, \theta_{c .2}\right)
$$

Under the assumption that the IPC utilizes all the sets of pitch angles on the domain $S_{I}\left(\theta_{c .1}, \theta_{c .2}\right)$ evenly, the average of $F_{\text {ave.radial }}\left(\theta_{c .1}, \theta_{c .2}\right)$ and $F_{\text {ave.axial }}\left(\theta_{c .1}, \theta_{c .2}\right)$ are obtained by:

$$
\begin{aligned}
& F_{\text {ave.ave.radial }}=\frac{\iint_{I}\left(\theta_{c .1} \theta_{c .2}\right)}{F_{\text {ave.radial }}\left(\theta_{c .1}, \theta_{c .2}\right) \cdot d \theta_{c .1} \cdot d \theta_{c .2}} \\
& F_{\text {ave.ave.axial }}=\frac{\iint_{S_{I}\left(\theta_{c .1}, \theta_{c .2}\right)} F_{\text {ave.axial }}\left(\theta_{c .1}, \theta_{c .2}\right) \cdot d \theta_{c .1} \cdot d \theta_{c .2}}{\iint_{S_{I}\left(\theta_{c .1}, \theta_{c .2}\right)} d \theta_{c .1} \cdot d \theta_{c .2}}
\end{aligned}
$$

In this paper, it is assumed that the forces in Equation (28) are treated as the representative radial and axial forces of the bearing to establish its life span.

Finally, the basic rating life span of bearing is predicted by [20]:

$$
\begin{gathered}
L_{\text {rev.ipc }}=\left[\frac{C}{P_{a . i p c}}\right]^{E} \cdot 10^{6}(\text { rev }) \\
P_{a . i p c}=X_{D} \cdot F_{\text {ave.ave.radial }}+Y_{D} \cdot F_{\text {ave.ave.axial }}
\end{gathered}
$$

where $C$ is a bearing dynamic capacity and the exponent of the life equation $E$ is $10 / 3$ for the roller bearing [20]. Due to the low rotating speed of the rotorblades and the expectation of a long life cycle, the roller bearing has been selected for this study. Also, $P_{a . i p c}, X_{D}$ and $Y_{D}$ are the dynamic equivalent of a dynamic load of bearing, a radial load factor, and an axial load factor, respectively. Here, theload factors $X_{D}$ and $Y_{D}$ are respectively chosen as 0.56 and 1.75 .

The entire process of prediction is briefly summarized in Figure 7. 


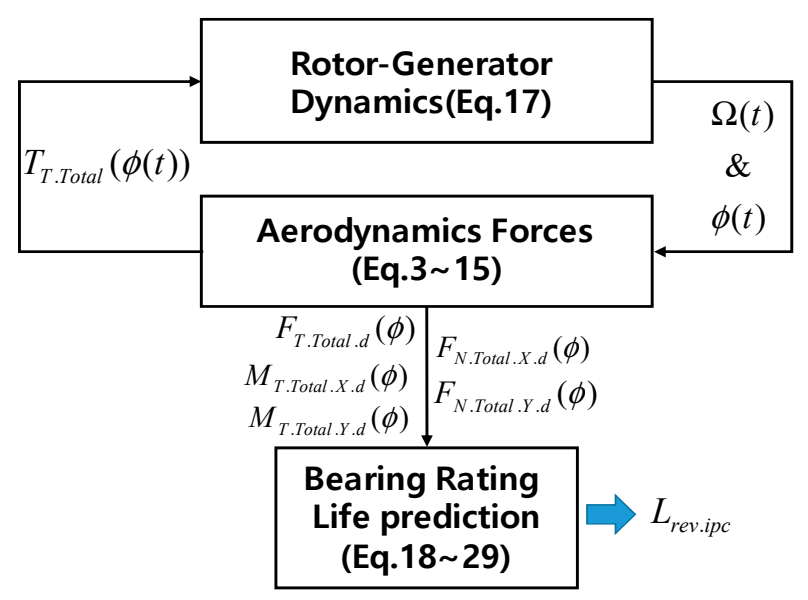

Figure 7. Entire process of prediction for the bearing rating life.

\section{Numerical Simulation Results}

Utilizing the model derived in Section 2 and the prediction of the bearing life span in Section 3, the life span of the primary bearing for a proposed 5-MW two-blade wind turbine system has been numerically investigated. The parameters of the proposed system are summarized in Table 1.

Table 1. System parameters for the numerical simulations.

\begin{tabular}{l} 
Parameters \\
\hline Masses of blades and shaft: $m_{B}=18 \mathrm{~kg} /$ blade and $m_{S}=500 \mathrm{~kg}$ \\
Blade radial length and hub height: $R=60 \mathrm{~m}$ and $Z_{0}=80 \mathrm{~m}$ \\
Total length of shaft: $L=8 \mathrm{~m}$ \\
Distance between the centers of shaft and geared generator unit: $4 \mathrm{~m}$ \\
Distance between the primary bearing and geared generator unit: $6.8 \mathrm{~m}$ \\
Control ranges of pitch angles: $0^{\circ} \leq \theta_{c .1}, \theta_{c .2} \leq 30^{\circ}$ \\
\hline
\end{tabular}

In Figure 8, the characteristics of the NACA64-A17 blade used in this paper are introduced. (a) and (b) of Figure 8 respectively present the chord lengths $(c)$ and the designed base blade pitch angles $\theta_{0}$ with respect to the radial direction of the blade $(r)$. The lift and drag coefficients $C_{L}(\alpha)$ and $C_{D}(\alpha)$ for the angle of attack $\alpha$ are shown in (c) and (d) of Figure 8. Also, the forces in Equations (22) and (23) are computed according to the number of segments for blade element $n$ in the radial direction and shown in (e) and (f) of Figure 8. Since Equations (14) and (15) are discrete, the selection of $n$ is important to approximate the lift and drag forces accurately. It can be seen from (e) of Figure 8 that the values of forces are converged as $n$ increases. Here, $n$ is selected to be 180 based on the observation from (f) of Figure 8.

According to various wind speeds at the hub $\left(V_{m}=10 \mathrm{~m} / \mathrm{s}, 12 \mathrm{~m} / \mathrm{s}, 14 \mathrm{~m} / \mathrm{s}, 16 \mathrm{~m} / \mathrm{s}, 18 \mathrm{~m} / \mathrm{s}\right.$ and $\left.20 \mathrm{~m} / \mathrm{s}\right)$, the average steady-state forces along the radial and axial directions of bearing(i.e, $F_{\text {ave.radial }}\left(\theta_{c .1}, \theta_{c .2}\right)$ in Equation (22) and $F_{\text {ave.axial }}\left(\theta_{c .1}, \theta_{c .2}\right)$ in Equation (23)) for all the possible sets of blade pitch angles $0^{\circ} \leq \theta_{c .1}, \theta_{c .2} \leq 30^{\circ}$ are shown in Figures 9 and 10. The results in the first row of Figures 9 and 10 indicate the distribution of $F_{\text {ave.axial }}\left(\theta_{c .1}, \theta_{c .2}\right)$. On the other hand, the outcomes in the second row represent the allocation of $F_{\text {ave.radial }}\left(\theta_{c .1}, \theta_{c .2}\right)$. Areas filled with red asterisks indicate the desired power range between 4.8-5.2 MW. The operational domain by IPC, $S_{I}\left(\theta_{c .1}, \theta_{c .2}\right)$, is plotted using the solid line in Figures 9 and 10, where the manipulation parameter $\varepsilon=15$ is used. It is found that the distribution of $F_{\text {ave.radial }}\left(\theta_{c .1}, \theta_{c .2}\right)$ is symmetrically characterized with respect to the reference angles $\theta_{c .1}=\theta_{c .2}$, and $F_{\text {ave.axial }}\left(\theta_{c .1}, \theta_{c .2}\right)$ tends to be decreased as the pitch angles become higher. Also, it is obvious that both $F_{\text {ave.radial }}\left(\theta_{c .1}, \theta_{c .2}\right)$ and $F_{\text {ave.axial }}\left(\theta_{c .1}, \theta_{c .2}\right)$ are clearly augmented as $V_{m}$ increases. 
(a)

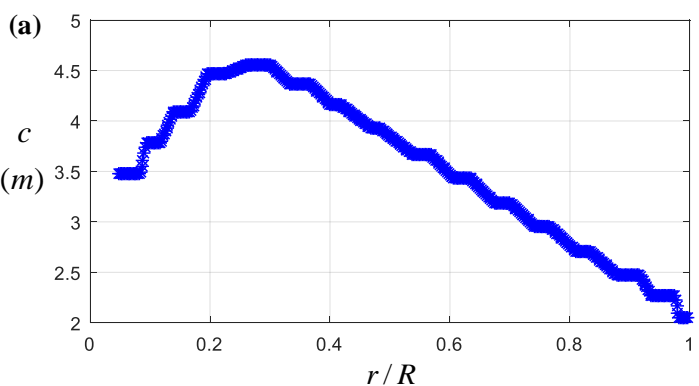

(c)
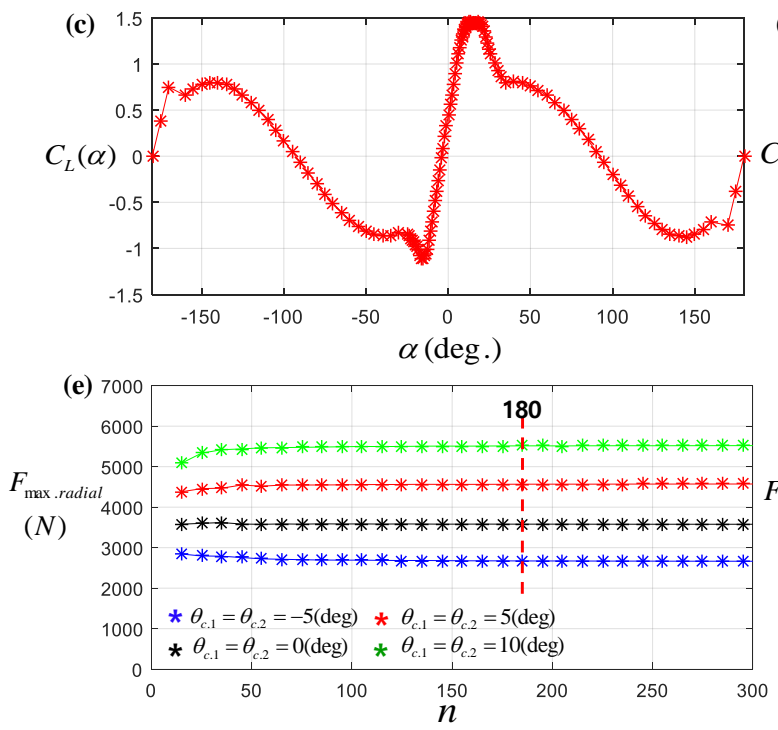

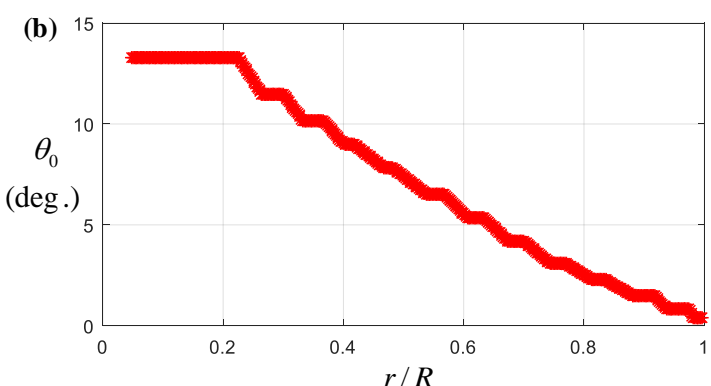

(d)
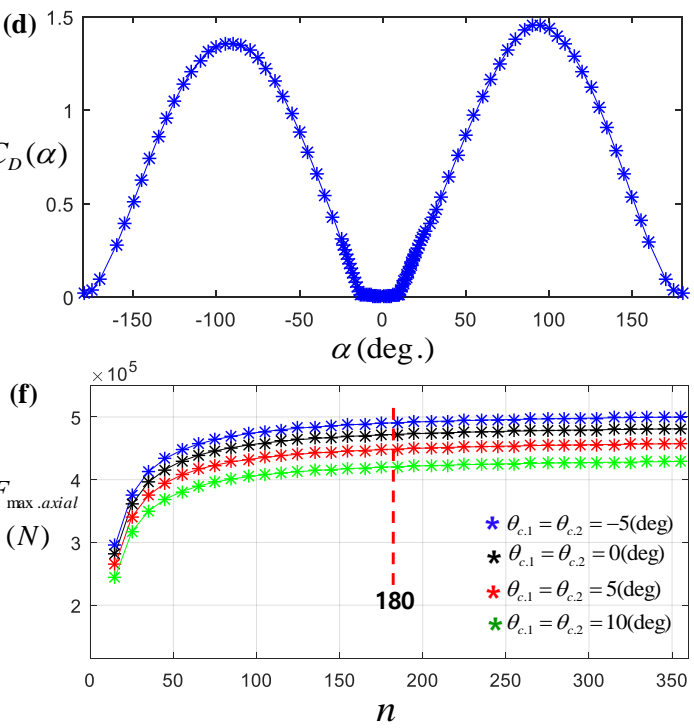

Figure 8. The characteristics of the NACA64-A17 blade ((a) and (b) for $c$ and $\theta_{0},(\mathbf{c})$ and (d) for $C_{L}(\alpha)$ and $C_{D}(\alpha)$, and (e) and (f) for the forces with $\left.n\right)$.

Before proceeding, let's consider the following sub-domain within $S_{I}\left(\theta_{c .1}, \theta_{c .2}\right)$, which is plotted using the dotted line in Figures 9 and 10, which is the control region of the CPC:

$$
S_{I I}\left(\theta_{c .1}, \theta_{c .2}\right)=\left\{\theta_{c .1}, \theta_{c .2} \mid \theta_{c . \min } \leq \theta_{c .1}, \theta_{c .2} \leq \theta_{c . \max }, \theta_{c .1}=\theta_{c .2}\right\} \cap S_{P}\left(\theta_{c .1}, \theta_{c .2}\right)
$$

Consequently, based on the domain $S_{I I}\left(\theta_{c .1}, \theta_{c .2}\right)$ above, the average forces (denoted by $F_{\text {ave.ave.radial.cpc }}$ and $\left.F_{\text {ave.ave.axial.cpc }}\right)$ of the bearing are computed as follows:

$$
\begin{aligned}
F_{\text {ave.ave.radial.cpc }} & =\frac{\int_{S_{I I}\left(\theta_{c .1}, \theta_{c .2}\right)} F_{\text {ave.radial }}\left(\theta_{c .1}\right) \cdot \sqrt{2} \cdot d \theta_{c .1}}{\int_{S_{I I}\left(\theta_{c .1}, \theta_{c .2}\right)} \sqrt{2} \cdot d \theta_{c .1}} \\
F_{\text {ave.ave.axial.cpc }} & =\frac{\int_{S_{I I}\left(\theta_{c .1}, \theta_{c .2}\right)} F_{\max . a x i a l}\left(\theta_{c .1}\right) \cdot \sqrt{2} \cdot d \theta_{c .1}}{\int_{S_{I I}\left(\theta_{c .1}, \theta_{c .2}\right)} \sqrt{2} \cdot d \theta_{c .1}}
\end{aligned}
$$

The bearing life span based on $S_{I I}\left(\theta_{c .1}, \theta_{c .2}\right)$ is predicted by:

$$
\begin{gathered}
L_{r e v . c p c}=\left[\frac{C}{P_{a . c p c}}\right]^{E} \cdot 10^{6} \\
P_{a . c p c}=X_{D} \cdot F_{\text {ave.ave.radial.cpc }}+Y_{D} \cdot F_{\text {ave.ave.axial.cpc }}
\end{gathered}
$$



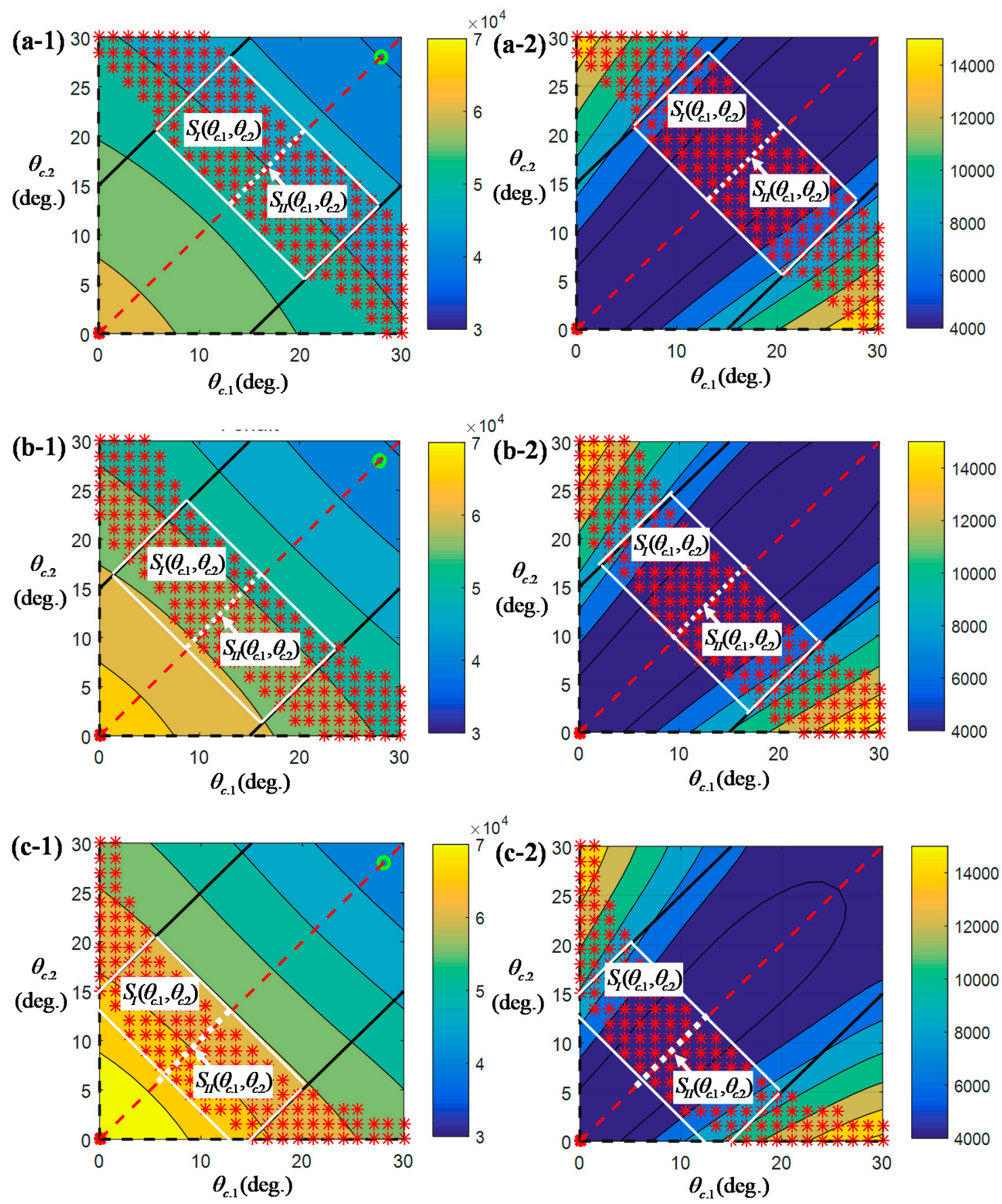

Figure 9. Average steady-state radial and axial forces, $F_{\text {ave.radial }}\left(\theta_{c .1}, \theta_{c .2}\right)$ and $F_{\text {ave.axial }}\left(\theta_{c .1}, \theta_{c .2}\right)$, on bearing with various wind speeds ((a-1) and (a-2) for $V_{m}=10 \mathrm{~m} / \mathrm{sec},(\mathbf{b}-\mathbf{1})$ and (b-2) for $V_{m}=$ $12 \mathrm{~m} / \mathrm{sec},(\mathbf{c}-\mathbf{1})$ and $(\mathbf{c}-2)$ for $\left.V_{m}=14 \mathrm{~m} / \mathrm{sec}\right)$. 

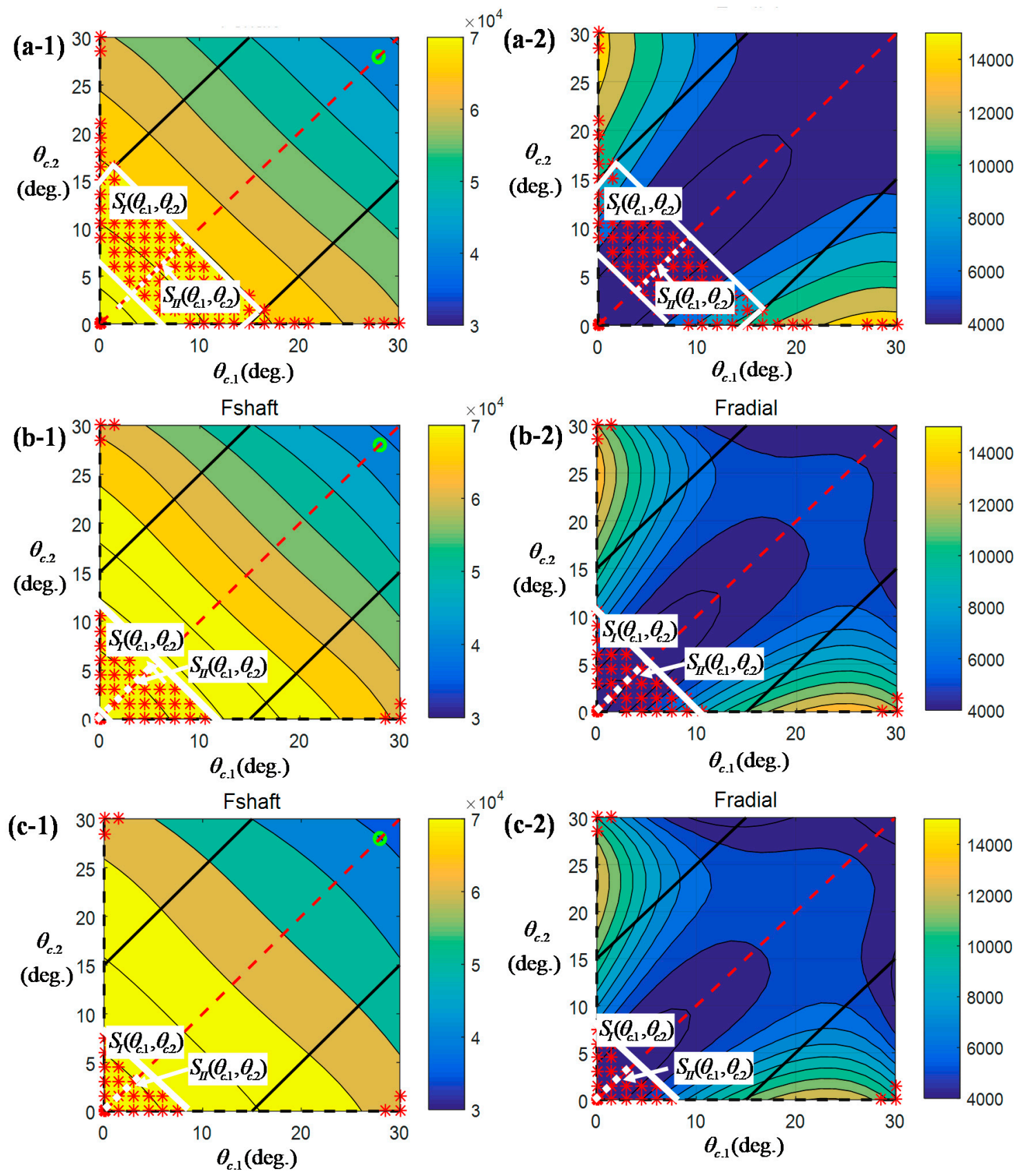

Figure 10. Average steady-state radial and axial forces, $F_{\text {ave.radial }}\left(\theta_{c .1}, \theta_{c .2}\right)$ and $F_{\text {ave.axial }}\left(\theta_{c .1}, \theta_{c .2}\right)$, on bearing with various wind speeds ((a-1) and (a-2) for $V_{m}=16 \mathrm{~m} / \mathrm{sec},(\mathbf{b}-\mathbf{1})$ and $(\mathbf{b}-\mathbf{2})$ for $V_{m}=18 \mathrm{~m} / \mathrm{sec}$, (c-1) and (c-2) for $V_{m}=20 \mathrm{~m} / \mathrm{sec}$ ).

To show the effectiveness and advantages of IPC for the bearing life span, $P_{a . c p c}$ in Equation (31b) is finally compared with $P_{a . i p c}$ in Equation (29b), and the results are shown in Figure 11. It is observed that the loads $P_{a . i p c}$ are almost identical to or slightly larger than $P_{a . c p c}$ for $10 \leq V_{m} \leq 12$. However, it is clear that the $P_{a . i p c}$ values are smaller than $P_{a . c p c}$ for $V_{m}>12$. The results evidently show $u$ s that the IPC-based control domain is more advantageous to prolong the bearing life span than the CPC-based one for higher wind speed.In other words, for $V_{m}>12$, it can be said that more various regulated pitch control angles are required to mitigate loads applied to the mechanical unit compared to the control capability of CPC (i.e., $\left.\theta_{c .1}=\theta_{c .2}\right)$. 
Additionally, Figure 12 contains the bearing span $L_{r e v . i p c}$ relative to the life $L_{r e v . c p c}$ for given wind speeds. The results roughly indicate the possibility that the bearing life span in an IPC-based wind turbine system will be approximately $10 \%$ to $25 \%$ longer than that of a CPC-based system.

From the trends shown in Figures 11 and 12, it is predicted that the control domain of IPC is significantly beneficial to mitigate the load of bearing resulting in expand its life span for the ranges of high wind speeds, which possibly cause structural impacts or damages.

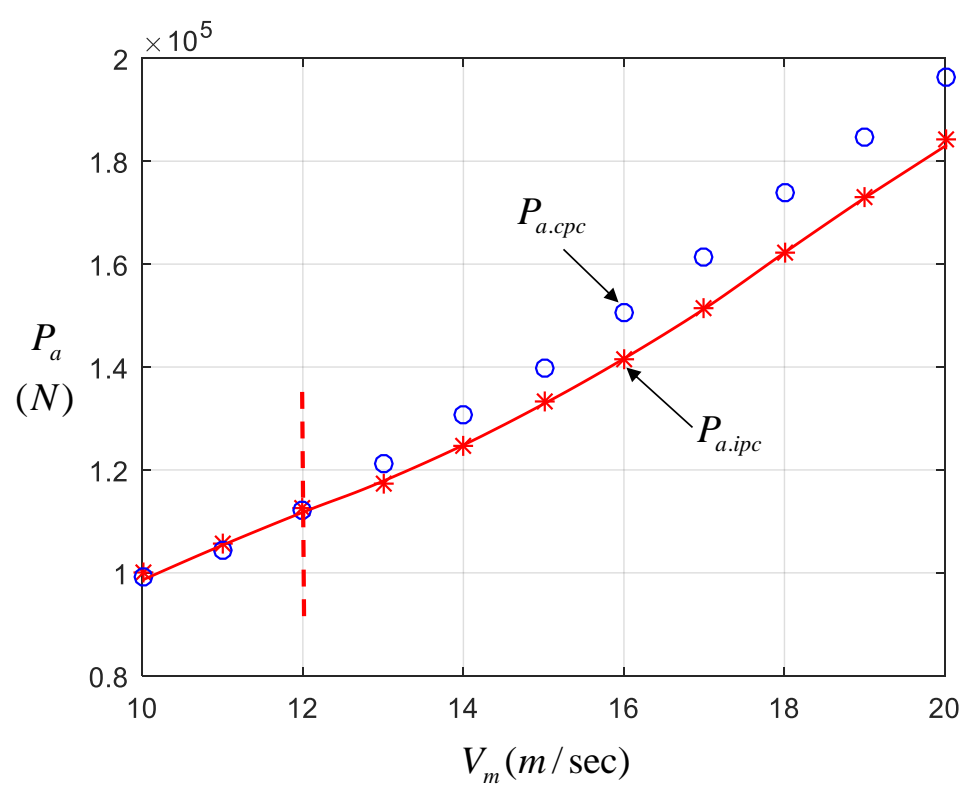

Figure 11. Dynamic equivalent dynamic loads of bearing $P_{a}$ (for individual pitch control, or IPC) and $P_{a . c}$ (for collective pitch control, or CPC) for various wind speeds.

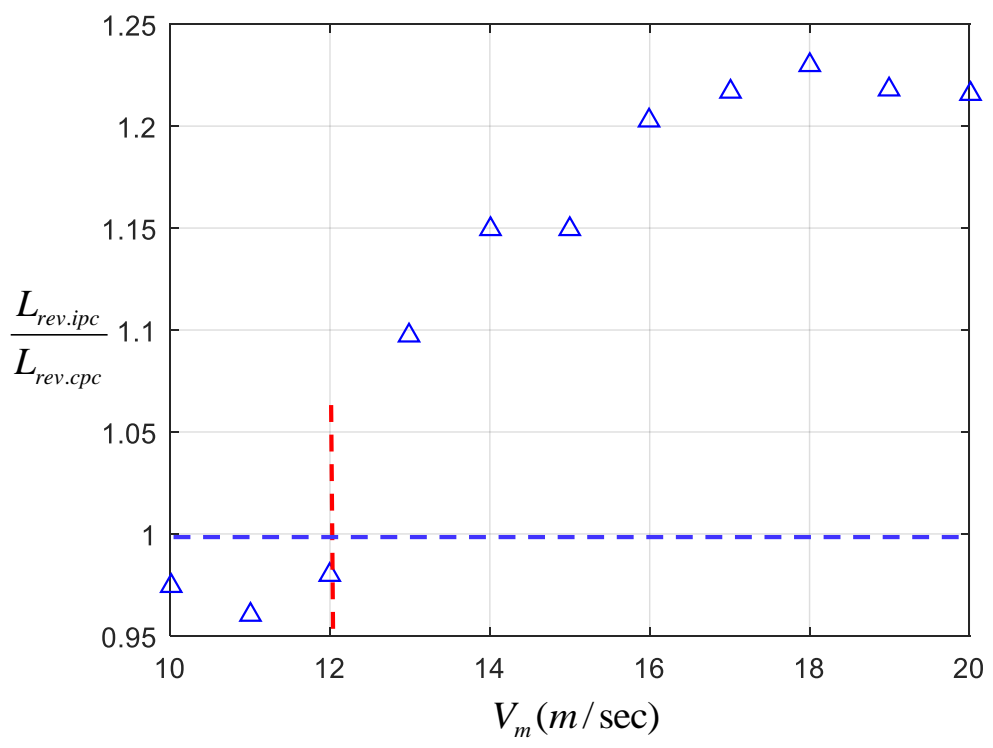

Figure 12. The ratio of life spans of bearing $L_{r e v . i p c} / L_{r e v . c p c}$ for various wind speeds.

\section{Conclusions}

This study focuses on the possible influence of the primary bearing life span of a two-blade 5-MW wind turbinesystem according to two different admissible control domains (IPC versus CPC). The mathematical model of blades-rotor-shaft-bearing integrity in the wind turbine system has been developed based on the first principle theory together with static force balance, and it is assumed that the WT model is influenced by inhomogeneous wind shear. The dynamic equivalent dynamic 
load of the bearinghas been calculated based on the region of loads applied to the bearing, satisfying both appropriate power levelsand allowable pitch control anglesof IPC.Eventually, the life span of the primary bearing has been predicted based on ISO 281 in [20].

Additionally, the predicted life span has been compared with the life span of the bearing obtained based on the control domain where CPC possibly produces.

In the range of high wind speeds(above $12 \mathrm{~m} / \mathrm{s}$ ) where the regulated control of the blades pitch angle is usually required, it is found that the results show the possibility that bearing life in an IPC-based wind turbine system will be approximately $10 \%$ to $25 \%$ longer than a CPC-based system. Considering the presented results, it is hoped that this work will provide important insights for ones who are majorly concerned with the design and selection of the primary bearing of the IPC-based wind turbine system.

Author Contributions: Conceptualization, D.-Y.J. and B.-Y.K.; methodology, D.-Y.J. and B.-Y.K.; software, D.-Y.J. and B.-Y.K.; validation, D.-Y.J. and B.-Y.K.; formal analysis, D.-Y.J. and B.-Y.K.; investigation, B.-Y.K. and D.-Y.J.; resources, B.-Y.K.; data curation, B.-Y.K.; writing-original draft preparation, D.-Y.J. and B.-Y.K.; writing-review and editing, B.-Y.K. and D.-Y.J.; visualization, D.-Y.J. and B.-Y.K.; supervision D.-Y.J. and B.-Y.K.; project administration, B.-Y.K. and D.-Y.J.; funding acquisition, B.-Y.K. and D.-Y.J.

Funding: This work was supported by the KETEP as Human Resources Development Programs (Grant No. 20174010201350). Also, it was supported by the KETEP and the MOTIE of the Republic of Korea (No. 20194030202300).

Conflicts of Interest: The authors declare no conflict of interest.

\section{References}

1. Tavner, P.J.; Xiang, J.; Spinato, F. Reliability analysis for wind turbines. Wind Energy 2007, 10, 1-18. [CrossRef]

2. Arabian-Hoseynabadi, H.; Oraee, H.; Tavner, P.J. Failure Modes and Effects Analysis (FMEA) for wind turbines. Electr. Power Energy Syst. 2010, 32, 817-824. [CrossRef]

3. Gallego-Calderon, J.; Natarajan, A.; Dimitrov, N.K. Effects of Bearing Configuration in Wind Turbine Gearbox Reliability. Energy Procedia 2015, 80, 392-400. [CrossRef]

4. Harris, T.; Rumbarger, J.H.; Butterfield, C.P. Wind Turbine Design Guideline DG03: Yaw and Pitch Rolling Bearing Life; National Renewable Energy Laboratory: Golden, CO, USA, 2009.

5. Jiang, Z.; Hu, W.; Dong, W.; Gao, Z.; Ren, Z. Structural reliability analysis of wind turbines: A review. Energies 2017, 10, 2099. [CrossRef]

6. Herp, J.; Ramezani, M.H.; Bach-Andersen, M.; Pedersen, N.L.; Nadimi, E.S. Bayesian state prediction of wind turbine bearing failure. Renew. Energy 2018, 116, 164-172. [CrossRef]

7. Vidal, Y.; Tutivén, C.; Rodellar, J.; Acho, L. Fault diagnosis and fault-tolerant control ofwind turbines via a discrete time controller with a disturbance compensator. Energies 2015, 8, 4300-4316. [CrossRef]

8. Niebsch, J.; Ramlau, R. Simultaneous estimation of mass and aerodynamic rotor imbalances for wind turbines. J. Math. Ind. 2014, 4, 1-19. [CrossRef]

9. Niebsch, J.; Ramlau, R.; Nguyen, T.T. Mass and Aerodynamic imbalance estimates of wind turbines. Energies 2010, 3, 696-710. [CrossRef]

10. Liu, X.; Gao, Z.; Chen, M.Z.Q. Takagi-Sugeno Fuzzy Model Based Fault Estimation and Signal Compensation With Application to Wind Turbines. IEEE Trans. Ind. Electron. 2017, 64, 5678-5689. [CrossRef]

11. Kusiak, A.; Verma, A. A Data-Driven Approach for Monitoring Blade Pitch Faults in Wind Turbines. IEEE Trans. Sustain. Energy 2010, 2, 87-96. [CrossRef]

12. Yang, W.; Tavner, P.J.; Crabtree, C.J.; Feng, Y.; Qiu, Y. Wind turbine condition monitoring: Technical and commercial challenges. Wind Energy 2014, 17, 673-693. [CrossRef]

13. García Márquez, F.P.; Tobias, A.M.; Pinar Pérez, J.M.; Papaelias, M. Condition monitoring of wind turbines: Techniques and methods. Renew. Energy 2012, 46, 169-178. [CrossRef]

14. Gao, Z.; Sheng, S. Real-time monitoring, prognosis, and resilient control for wind turbine systems. Renew. Energy 2018, 116, 1-4. [CrossRef]

15. Bossanyi, E.A. Individual blade pitch control for load reduction. Wind Energy 2003, 6, 119-128. [CrossRef]

16. El-Henaoui, S. Individual Pitch Control and Its Impact. Wind Systems Magazine, 5 July 2012; 1-6. 
17. Gong, X.; Qiao, W. Simulation investigation of wind turbine imbalance faults. In Proceedings of the 2010 International Conference on Power System Technology: Technological Innovations Making Power Grid Smarter, Hangzhou, China, 24-28 October 2011.

18. Selvam, K.; Kanev, S.; van Wingerden, J.W.; van Engelen, T.; Verhaegen, M. Feedback-feedforward individual pitch control for wind turbine load reduction. Int. J. Robust Nonlinear Control 2009, 19, 72-91. [CrossRef]

19. Njiri, J.G.; Söffker, D. State-of-the-art in wind turbine control: Trends and challenges. Renew. Sustain. Energy Rev. 2016, 60, 377-393. [CrossRef]

20. ISO. ISO 281 Rolling Bearings-Dynamic Load Ratings and Rating Life, 2nd ed.; International Organization for Standardization (ISO): Geneva, Switzerland, 2007.

(C) 2019 by the authors. Licensee MDPI, Basel, Switzerland. This article is an open access article distributed under the terms and conditions of the Creative Commons Attribution (CC BY) license (http://creativecommons.org/licenses/by/4.0/). 